\title{
Producing KDP and DKDP Crystals for the NIF Laser
}

A. K. Burnham, H. F. Robey, N. P. Zaitseva, J. J. De Yoreo, R. A. Hawley-Fedder, M. Runkel, M. Yan, M. Staggs, S. A. Couture, R. L. Combs, R. C. Montesanti, P. J. Wegner, and L. J. Atherton

\section{September 2, 1999}

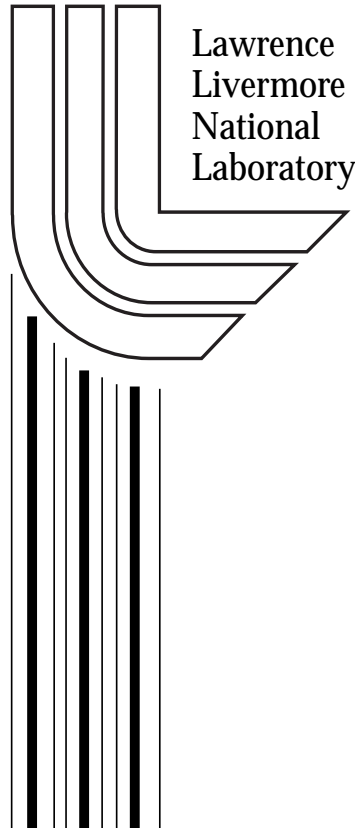




\section{DISCLAIMER}

This document was prepared as an account of work sponsored by an agency of the United States Government. Neither the United States Government nor the University of California nor any of their employees, makes any warranty, express or implied, or assumes any legal liability or responsibility for the accuracy, completeness, or usefulness of any information, apparatus, product, or process disclosed, or represents that its use would not infringe privately owned rights. Reference herein to any specific commercial product, process, or service by trade name, trademark, manufacturer, or otherwise, does not necessarily constitute or imply its endorsement, recommendation, or favoring by the United States Government or the University of California. The views and opinions of authors expressed herein do not necessarily state or reflect those of the United States Government or the University of California, and shall not be used for advertising or product endorsement purposes.

Work performed under the auspices of the U. S. Department of Energy by the University of California Lawrence Livermore National Laboratory under Contract W-7405-Eng-48.

This report has been reproduced

directly from the best available copy.

Available to DOE and DOE contractors from the

Office of Scientific and Technical Information

P.O. Box 62, Oak Ridge, TN 37831

Prices available from (423) 576-8401

http:/ /apollo.osti.gov/bridge/

Available to the public from the

National Technical Information Service

U.S. Department of Commerce

5285 Port Royal Rd.,

Springfield, VA 22161

http://www.ntis.gov/

OR

Lawrence Livermore National Laboratory

Technical Information Department's Digital Library

http://www.llnl.gov/tid/Library.html 


\title{
Producing KDP and DKDP CRystals FOR THE NIF LASER
}

\author{
A. K. Burnham \\ R. A. Hawley-Fedder \\ R. L. Combs \\ H. F. Robey \\ M. Runkel \\ R. C. Montesanti \\ N. P. Zaitseva \\ M. Yan \\ P. J. Wegner \\ J. J. De Yoreo \\ M. Staggs \\ L. J. Atherton
}

S. A. Couture

$\mathrm{T}$ he cost and physics requirements of the NIF have established two important roles for potassium dihydrogen phosphate (KDP) crystals.

1. To extract more laser energy per unit of flashlamp light and laser glass, the NIF has adopted a multipass architecture as shown in Figure 1. Light is injected in the transport spatial filter, first traverses the power amplifiers, and then is directed to main amplifiers, where it makes four passes before being redirected through the power amplifiers towards the target. To enable the multipass of the main amplifiers, a KDP-containing Pockels cell rotates the polarization of the beam to make it either transmit through or reflect off a polarizer held at Brewster's angle within the main laser cavity. If transmitted, the light reflects off a mirror and makes another pass through the cavity. If reflected, it proceeds through the power amplifier to the target.

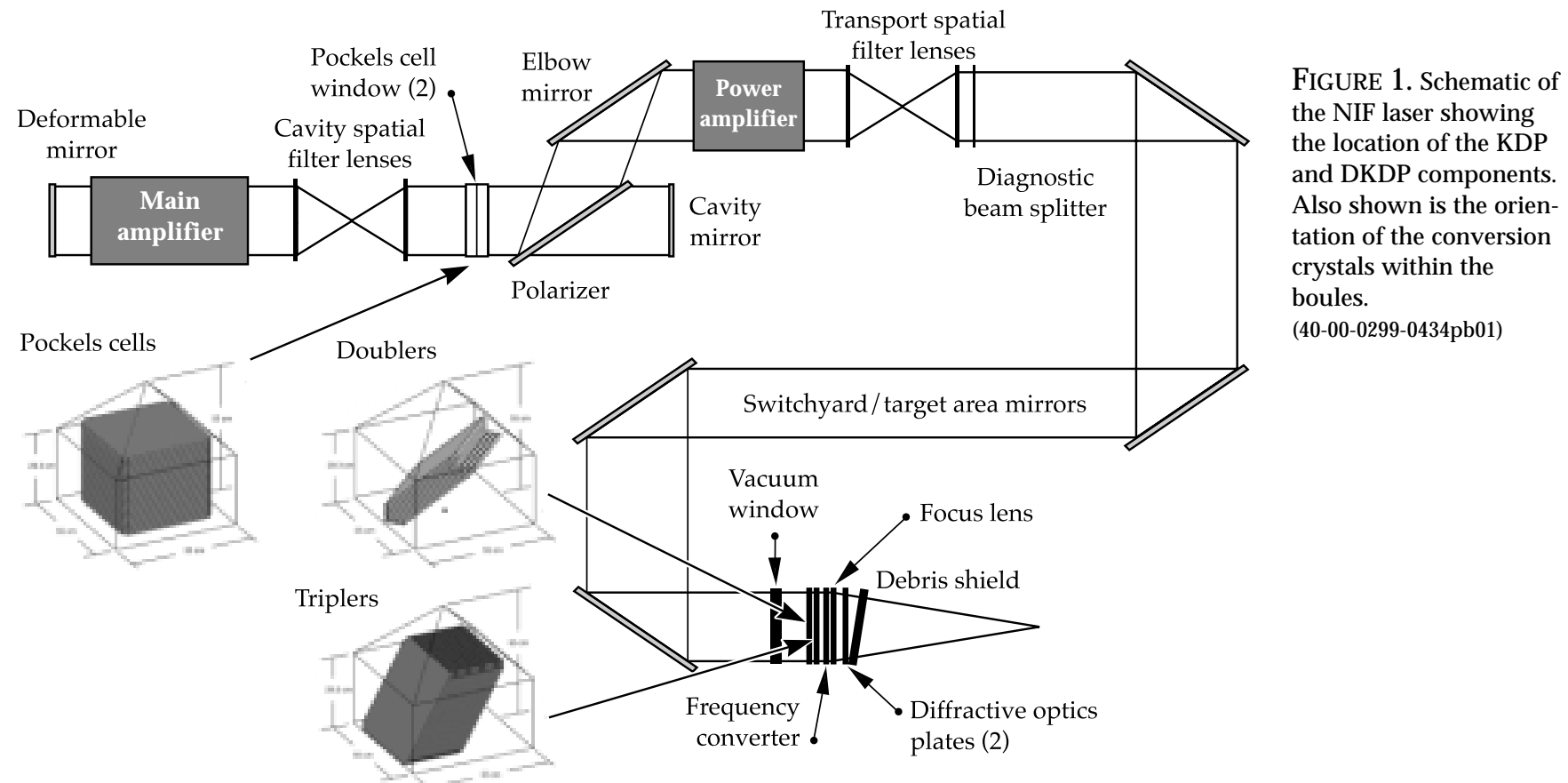


2. Implosions for ICF work far better at shorter wavelengths due to less generation of hot electrons, which preheat the fuel and make it harder to compress. Compromising between optic lifetime and implosion efficiency, both Nova and the NIF operate at a tripled frequency of the 1053-nm fundamental frequency of a neodymium glass laser. This tripling is accomplished by two crystals, one made of KDP and one made of deuterated KDP (DKDP). The first one mixes two 1053-nm photons to make 526-nm light, and the second one combines a residual 1053-nm photon with a 526-nm photon to make 351-nm light.

The locations of the Pockels cell and frequency conversion crystals in the laser are also shown in Figure 1, along with the orientation of the plates as they are cut from the crystal boule. Although all finished crystals will be $41 \mathrm{~cm}$ square, their different orientation with respect to the crystal axes, required in order to accomplish their different functions, causes different boule size requirements for the three types of finished crystals. The Pockels cell crystal is the easiest, since it is cut horizontally with respect to the base of the crystal. As a result a $43-\mathrm{cm}$ square boule is large enough, including a 1-cm buffer for finishing purposes, and the plates stack efficiently up to or even into the pyramidal cap, depending on the size of the base. Only about 15 of these small boules are needed. The KDP doubler crystal is the most challenging, as it is rotated in two axes with respect to the base. As a result, the minimum size base for a single doubler crystal is $51 \mathrm{~cm}$, and a symmetric $55-\mathrm{cm}$-square by 55 -cm-high boule will generate only six doublers, so nearly 35 of these boules will be required. A symmetric DKDP tripler must be a minimum of $55 \mathrm{~cm}$ high to be tall enough for a single tripler, but that minimum size will yield about 15 triplers.

Boules of both KDP and DKDP meeting NIF size and quality requirements have been grown by Cleveland Crystals, Inc. (CCI), by what is often called conventional growth. In this case, impurities in the growth solution poison growth of the vertical faces (prisms), thereby maintaining a cross section approximately equal to that of the original seed crystal as the pyramid faces grow. Unfortunately, this pyramidal growth is very slow, and it takes about two years to grow a crystal to NIF size. To provide more programmatic flexibility and reduce costs in the long run, we have developed an alternative technology commonly called rapid growth. Through a combination of higher temperatures and higher supersaturation of the growth solution, a NIF-size boule can be grown in 1 to 2 months from a small "point" seed. However, growing boules of adequate size is not sufficient. Care must be taken to prevent inclusions of growth solution and incorporation of atomically substituted impurities in the prism growth. Other issues important for meeting transmitted wavefront quality, absorption, and laser damage criteria must be addressed also.

During the past year, we made substantial progress towards bringing the rapid growth technology to the stage needed to supply most of the KDP and some of the DKDP needed for the NIF. This article reviews the technical hurdles that were overcome during this period and outlines some of the issues yet to be fully resolved. It also covers some of the efforts to transfer this technology to two potential vendors for NIF crystals-CCI and Inrad-as well as the development of crystal finishing technology.

\section{Crystal Growth}

For several years, the rapid growth process has reproducibly grown crystals of high visual quality up to about $20 \mathrm{~cm}$ in linear dimensions in tanks containing less than $100 \mathrm{~L}$ of solution. These systems demonstrated many of the important conditions needed to grow crystals of NIF quality, such as solution purity and ways to achieve adequate mass transfer at the growing crystal surface. Over the past year, this understanding has been applied at the 1000-L tank scale in order to improve yields of NIF-size boules to the point where rapid growth can become an industrial production process. This section reviews the fundamentals of the growth process and the particular problems that affect the commercial viability of rapid growth for NIF-scale boules. 
The fundamental property of nature enabling rapid crystal growth is that KDP can attain very large and stable supersaturations in solution. In other words, KDP will not spontaneously crystallize from solution when a solution is prepared at high temperature and then cooled so that the salt concentration is above its equilibrium solubility. This is because any protocrystal formed by a statistical fluctuation has to reach a minimum size before growth is thermodynamically favorable. (This same nucleation criterion occurs in many aspects of chemistry and physics.) Measurements have shown that stable supersaturations from $35 \%$ at $65^{\circ} \mathrm{C}$ to $100 \%$ at $10^{\circ} \mathrm{C}$ can be attained if the solution is thoroughly preheated to eliminate any nucleation sites, and stability is not affected by impurities at the level of tens to hundreds of parts per million. ${ }^{1}$ This supersaturation is much higher than the 3-20\% required for growing crystal faces at rates of 10-20 mm/day.

When a seed crystal is introduced into this supersaturated solution, the crystal immediately grows at a rate that depends on a variety of chemical kinetic and mass transfer factors. Practical experience over many years has shown that the best way to start this process is to first partially dissolve an oriented seed crystal of about $1 \mathrm{~cm}^{3}$ in size above the saturation temperature, then decrease the temperature until the solution supersaturation reaches about $3 \%$, at which time the seed "regenerates." ${ }^{2}$ Regeneration is a process in which a rectangular base and pyramid form over the partially dissolved, rounded seed crystal. A picture of a regenerated seed is shown in Figure 2. It is important to accomplish this regeneration rapidly (over 1-3 hours) so that each crystal face will have numerous imperfections called dislocations. The crystal grows by adding atoms from solution to a set of atomic steps that emanate from these dislocations. This configuration is called a growth hillock, and a microscopic picture of a growth hillock is shown in Figure $3 .^{3}$ As growth proceeds, the stronger growth hillocks crowd out the weaker ones, and favorable growth proceeds with one to four hillocks on each crystal face. Crystals continue to grow as long as the temperature is decreased to maintain appropriate supersaturations. The growing crystal is rotated back and forth on a horizontal platform with a washing machine-like action to maintain good mass transfer.

Even though the growth solution is stable with respect to homogeneous nucleation, occasional heterogeneous formation of a single unwanted seed at a variety of possible locations can cause the formation of unwanted crystals, which are generally first observed on the bottom of the tank. This crystal, being grown in nonoptimal conditions, usually cracks and subdivides, thereby seeding other parts of the tank. When one of these seeds inevitably lands on the product crystal, its quality will be spoiled and the run ruined. Eliminating these spurious crystals for the entire two months of a growth run continues to be one of the most important challenges for cost-effective production.

Impurities in solution are detrimental for a variety of reasons:

- They affect the growth rates of the prism faces.

- They can enhance the formation of inclusions of growth solution that reduce optical quality.

- They substitute into the atomic lattice in the prism sectors and cause inhomogeneities in the refractive index and loss of optical transmission by absorption.

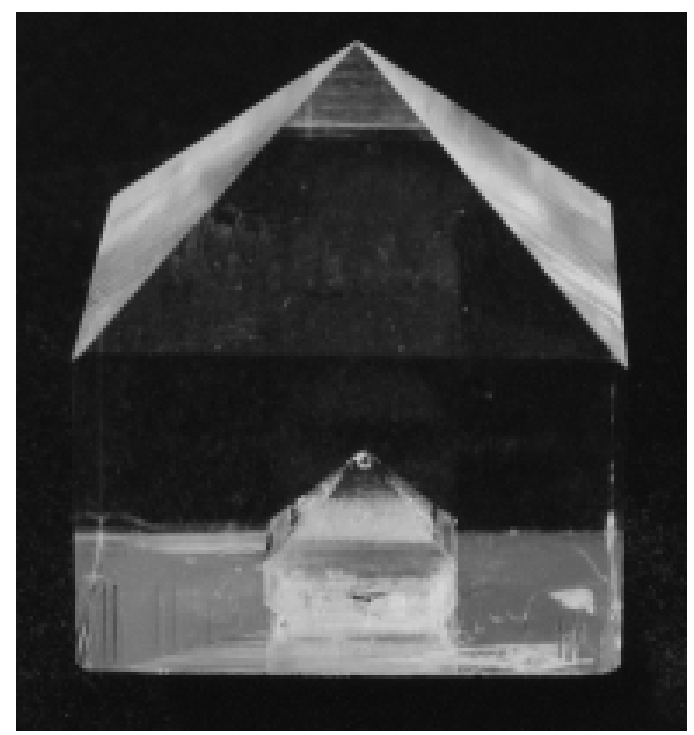

FIGURE 2. Photograph of a recently regenerated seed. The cloudy regeneration layer is covered with about $1 \mathrm{~cm}$ of clear growth. (40-00-0299-0435pb01) 
(b)

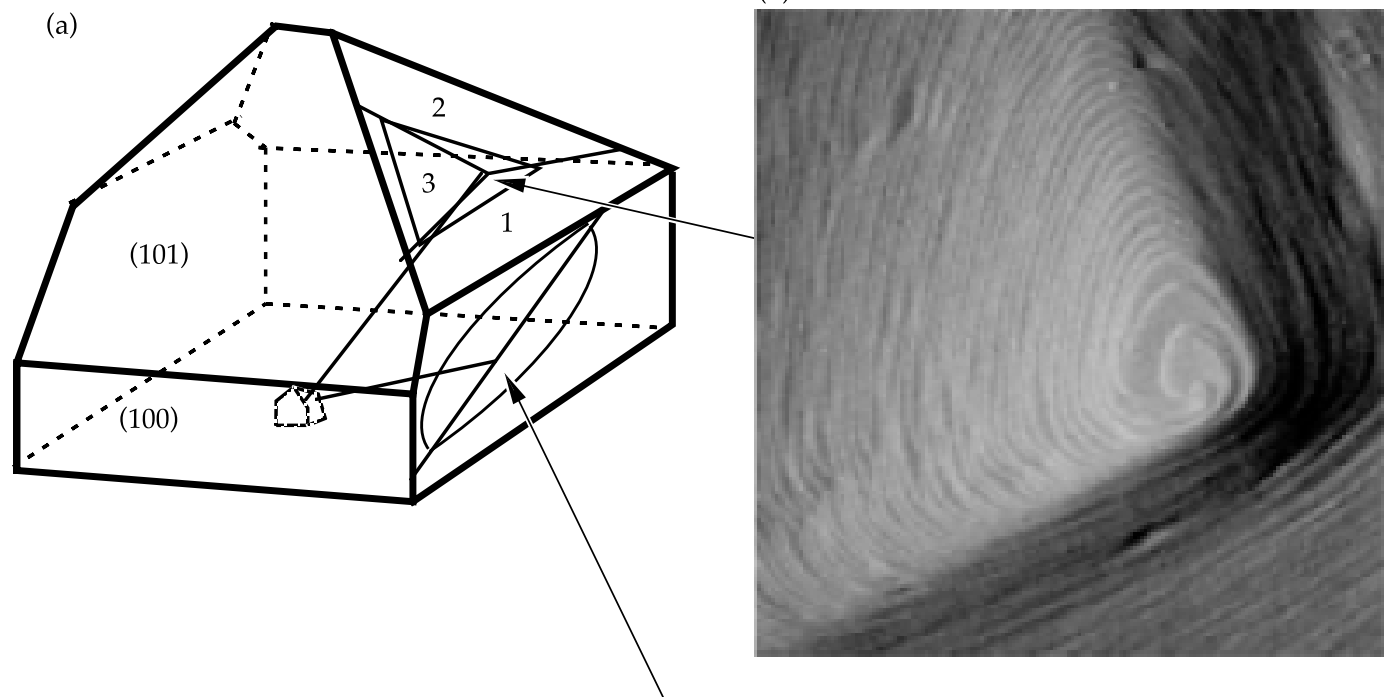

(c)

FIGURE 3. (a) Schematic of the crystal surfaces indicating where the atomic steps (pictured through an atomic force microscope) emanate from dislocations on the (b) pyramid and (c) prism. The resulting macroscopic feature is called a growth hillock. The crystal grows by adding atoms from solution at the edge of the steps. (40-00-0299-0436pb01)

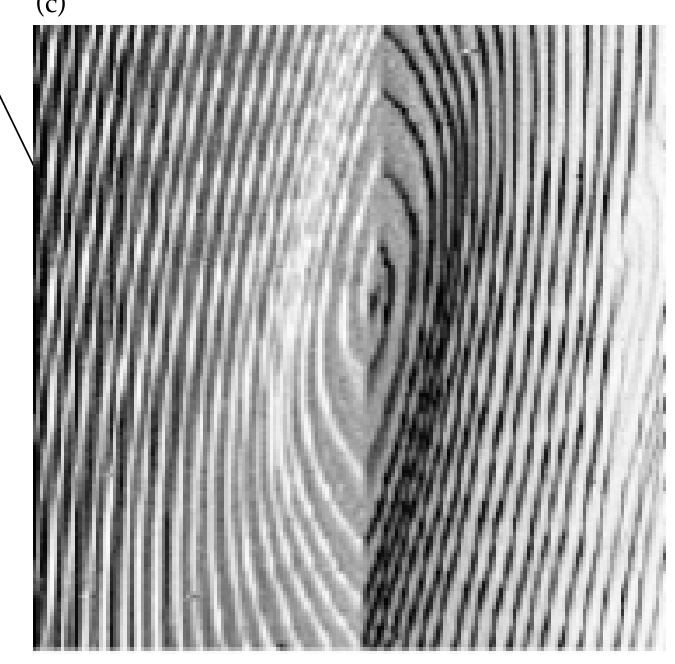

- They may form particulates that affect the laser damage threshold of the material.

While the chemical structure of the pyramid face causes typical ionic impurities to be rejected from the growing crystal, the chemical structure of the prism face causes them to be selectively absorbed and incorporated into the crystal. ${ }^{4} \mathrm{~A}$ few examples of this selective absorption and rejection are shown in Table 1. Fe is the most important impurity in terms of transmittance, because $\mathrm{FePO}_{4}$ is highly absorbing at $351 \mathrm{~nm}$, resulting in a maximum acceptable Fe concentration of $200 \mathrm{ppb}$ for salt from which DKDP triplers are to be grown.
TABLE 1. Concentrations of typical impurities in the raw material and in the pyramidal and prismatic sectors of KDP crystals.

$\begin{array}{lccc}\text { Impurity } & \begin{array}{c}\text { Raw } \\ \text { material }^{*}\end{array} & \begin{array}{l}\text { Pyramid* } \\ \text { B }\end{array} & \text { Prism* } \\ \mathrm{Na} & 1000 & \mathrm{ND} & \mathrm{ND} \\ \mathrm{Al} & 86,000 & \mathrm{ND} & \mathrm{ND} \\ \mathrm{Si} & 900 & 200 & 4400 \\ \mathrm{Ca} & 12,000 & <100 & 390 \\ \mathrm{Cr} & 3600 & \mathrm{ND} & \mathrm{ND} \\ \mathrm{Fe} & 2000 & 490 & 11,000 \\ & 5300 & 110 & 12,000 \\ \text { *Units of ng/g KDP } & & \\ \text { ND = not detected } & & \\ \end{array}$


Impurity incorporation into the prism face also affects the relationship between growth rate and supersaturation, as shown in Figure $4 .{ }^{5}$ At low supersaturations, impurities effectively stop prism growth, and this condition is called "the dead zone." Conventional growth occurs in this region, and only pure pyramid material is formed. Unfortunately, this corresponds to growth rates less than $1 \mathrm{~mm} /$ day, which results in growth times greater than one year for NIF-size boules. In the middle transition zone, relatively small changes in growth conditions can have a drastic effect on growth rate. As is typical for any stable, reliable industrial process, this region should be avoided. This leaves the highgrowth region as the most appropriate for development.

While the effect of impurities on growth rates is understood quantitatively over some range of conditions, it is not understood quantitatively for mixtures of impurities and over the wider temperature range used to grow crystals. Rather than attempt to quantify this parameter space in detail, our approach was instead to reduce impurities to the lowest practical level, which is also important for meeting other specifications, and use the qualitative principle of maintaining the highest possible growth rate to minimize the effect of impurities on growth instability. Once the necessary purity of the starting salt was attained ( $<0.5$ ppm impurities), the contribution of impurities from the Pyrex growth tanks was explored. Though usually inert, there is a finite rate of tank dissolution in the hot KDP solutions used for rapid growth. ${ }^{4}$ Using measured Pyrex dissolution rates and the uptake coefficients for various impurities in the prism sector, we have successfully modeled the buildup and eventual consumption of $\mathrm{Al}$ and $\mathrm{Fe}$ in the growth solution, ${ }^{6}$ as shown for $\mathrm{Al}$ in Figure 5. Elements such as B and $\mathrm{Si}$ are not absorbed in the crystal and continue to build up in the growth solution, while others such as $\mathrm{Ca}$ are roughly constant during each growth run but increase after each resaturation of the growth solution. Plastic tanks are being considered to eliminate this problem. Another important recent advance for maintaining crystal quality is the successful implementation of constant filtration to remove particulates that come from moving equipment or precipitation. ${ }^{7}$

At high growth rates, another problem becomes important. Variations in KDP concentration on the $\mu \mathrm{m}$ scale at the growing crystal steps can cause inclusions of growth solution. These inclusions can easily be large enough to cause more obscuration by scattering than can be tolerated in the laser. Figure 6 summarizes much historical data on the occurrence of pyramidal

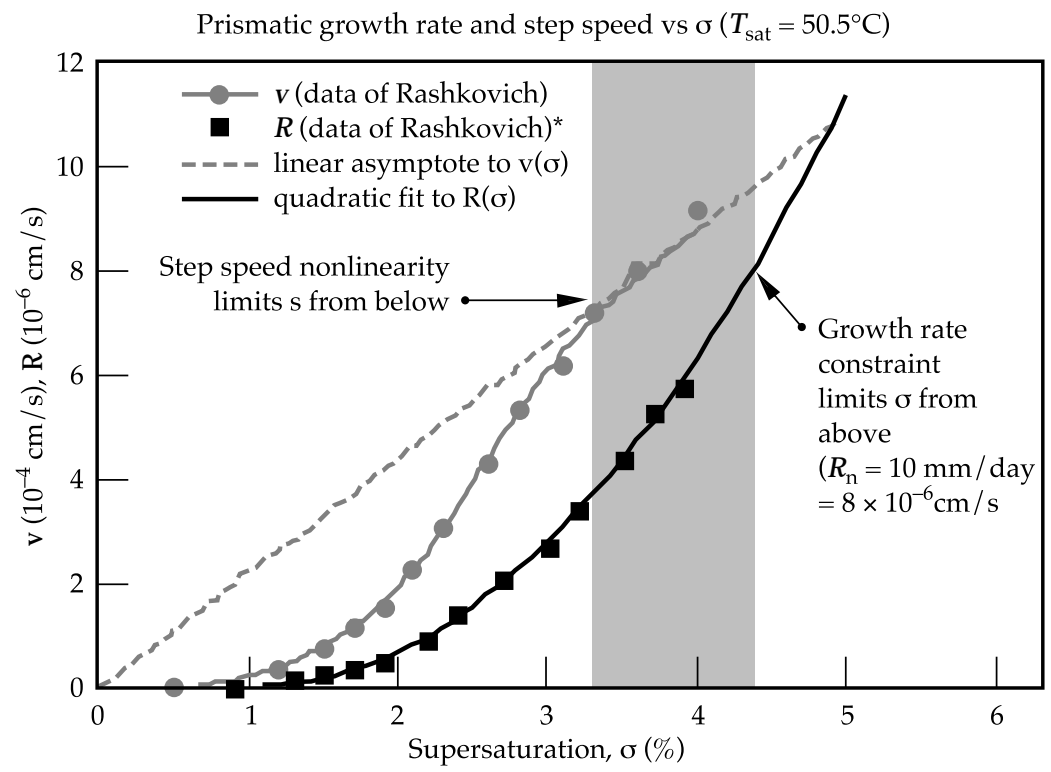

FIGURE 4. Effect of impurities on the step velocity and normal growth rate of KDP. The optimal growth rate is above the nonlinear region of step velocity and an upper bound determined by the uniformity of mass transfer. (40-00-0299-0437pb01) 
$\mathrm{Al}$ concentration for Run F-4

FIGURE 5. Comparison of measured and calculated $\mathrm{Al}$ concentration in the growth solution as a function of time. The $\mathrm{Al}$ concentration initially rises because the rate of glass tank dissolution dominates when the crystal is small; it later falls because the rate of uptake in the prism face increases with crystal size and exceeds the glass dissolution rate, which drops with temperature.

(40-00-0299-0438pb01)

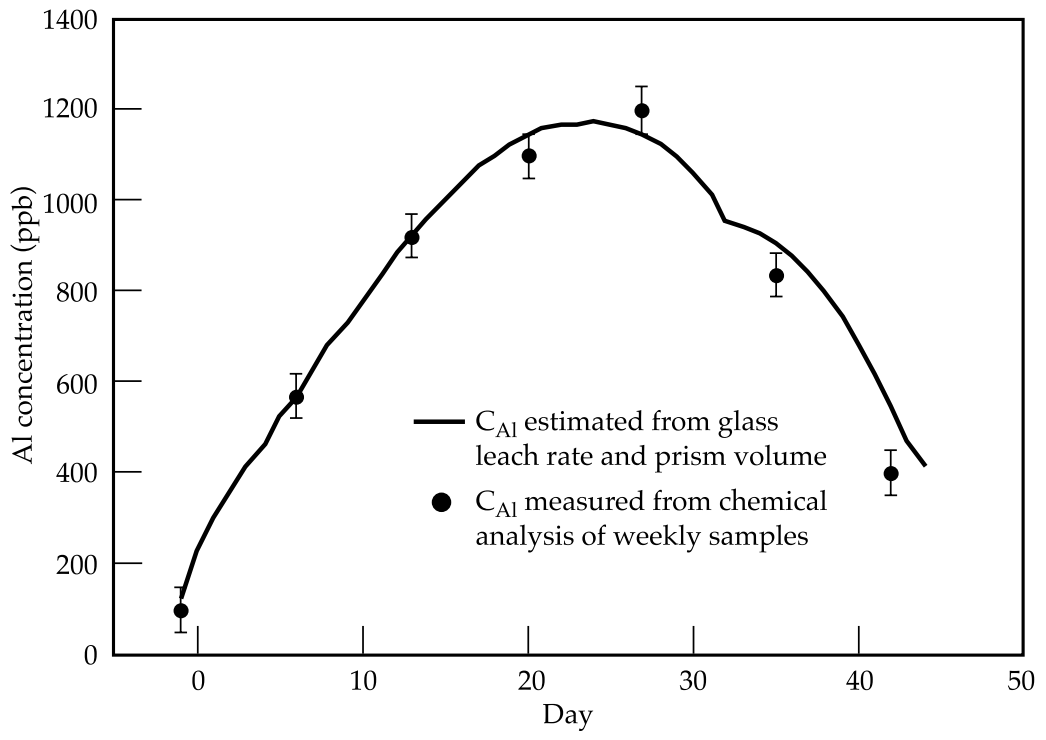

inclusions in 1000-L growth tanks through 1998, indicating that for low rotation rates pyramidal inclusions are much more prevalent at high growth rates. The same trend occurs for prismatic inclusions. This presents the crystal grower with a dilemma-how to avoid the detrimental effects of impurity buildup and associated degradation of prismatic KDP that occurs at slow growth rates while avoiding the potential formation of massive pyramidal inclusions at high growth rates.

Microscopic investigations, hydrodynamic modeling, and theoretical modeling have been combined to provide a good mechanistic understanding of the
FIGURE 6. Summary of 1000-L growth tank data showing the relationship between pyramidal inclusions and growth rates for slow and fast rotational regimes. For runs prior to late 1998, the rotational rate was typically $25 \mathrm{rpm}$, while the high rotation rate during the recent run represented by the filled squares was at $50 \mathrm{rpm}$. (40-00-0299-0439pb01)

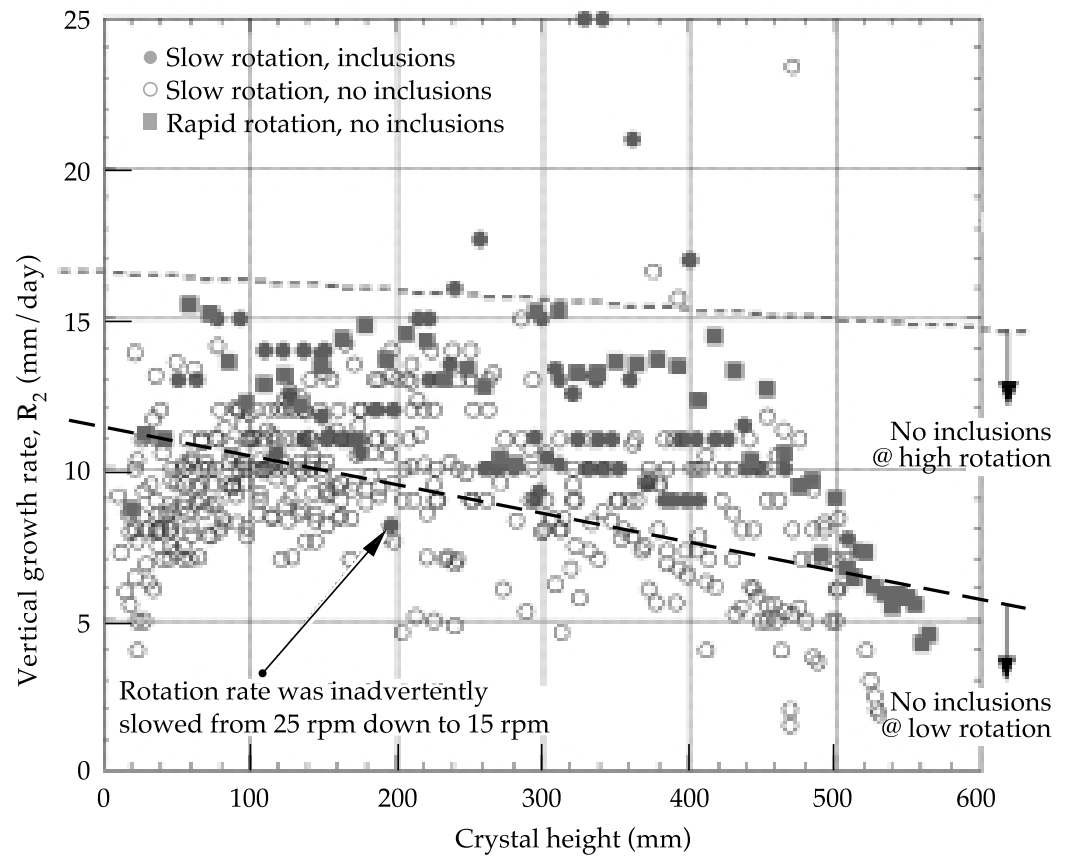


formation of inclusions. A micrograph of one type of unstable growth is shown in Figure 7, in which "fingering" is apparent on the advancing growth step. ${ }^{8}$ Although thermodynamics promote the filling of cavities between the fingers during slow growth, kinetics can cause the fingers to grow catastrophically, thereby surrounding and occluding growth solution. Solution moving in the opposite direction of the step advance is depleted in concentration as it moves past the tips of the fingers and towards the cavities, thereby causing a faster growth rate at the tip of the finger than at the base. Rapidly alternating the direction of flow helps prevent this catastrophic growth. A second type of instability involves the bunching and bending of elementary growth steps into macrosteps due to inadequate stirring. ${ }^{9}$ When macrosteps from two sides of a growth hillock bend around and approach each other from the opposite direction, a deep valley can be formed. Inclusions also tend to form in the vicinity of this valley. Valley formation can be minimized by rapid rotation, thereby keeping the solution concentration in the center of the crystal face closer in magnitude to that along the edges.

Through a combination of these fundamental studies and growth experiments at various scales over the past year, we have shown that better mass transfer by increased acceleration and rotation rates can increase the inclusion-free growth rate by 20 to $40 \%$ over the slow rotation limit shown in Figure 6. The best-quality NIF-size KDP boule grown to the

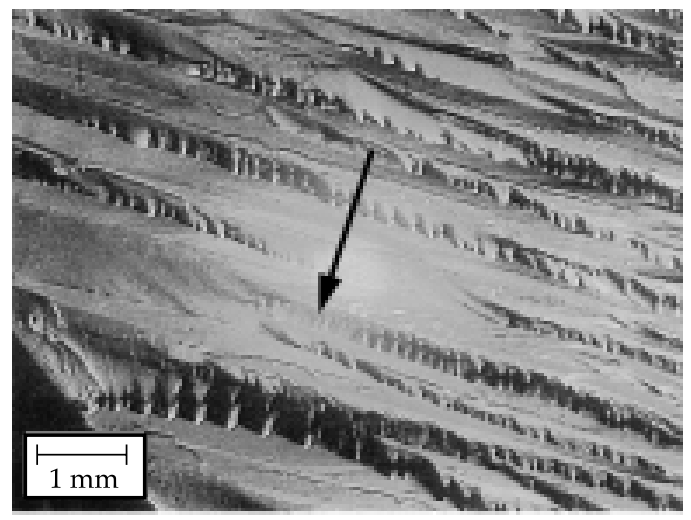

FIGURE 7. Fingering growth of macrosteps on the KDP surface. (40-00-0299-0440pb01) time of this writing, completed in late 1998, followed the solid-square growth trajectory also shown in Figure 6, substantially above that previously considered safe. An important aspect of achieving these higher rotation rates was the design and fabrication of streamlined Al growth platforms coated with a nonleaching Teflon-like coating.

The shape of the product crystal is also a practical problem. When grown rapidly from a pure solution intended to meet quality objectives, DKDP especially tends to grow with a height-to-width (aspect) ratio as low as 0.7. Since our circular growth platforms have a diameter of $90 \mathrm{~cm}$, the maximum symmetric-base is $63 \mathrm{~cm}$, which would produce a crystal only $44 \mathrm{~cm}$ hightoo short for triplers. A similar though less severe problem occurs for KDP. Improving aspect ratio by allowing more solution impurities to retard prism growth is undesirable, especially for DKDP, which is challenged to meet a more difficult 351-nm laser damage threshold. As a result, we are exploring a variety of ways to improve doubler and tripler yields by making more optimal shapes. One idea is using an off-center seed to promote asymmetric growth of the type shown in Figure 8a, which is appropriate for increased doubler yield. A method for triplers is to grow the DKDP boule horizontally, which increases aspect ratio (now rotated) by eliminating one growth prism and adding a second pyramid. Again very recently, a good-quality horizontal DKDP boule, shown in Figure 8b, was grown for the first time to NIF size. Successful shape control could increase conversion crystal yields by a factor of two over that from symmetric, vertically grown boules.

\section{Laser Damage}

At high laser fluences, KDP and DKDP damages in the bulk by forming pinpoint scattering sites a few micrometers in size. ${ }^{10}$ The basic consideration driving the laser damage specification is that this scattering should not exceed $0.1 \%$ of the laser light per optic traversed at the fluences expected for a 1.8-MJ ignition shot. The relevant fluences are an average of $12 \mathrm{~J} / \mathrm{cm}^{2}$ and $3 \sigma$ limit of $18 \mathrm{~J} / \mathrm{cm}^{2}$ for $1053-\mathrm{nm}$ light over $3 \mathrm{~ns}$ on the KDP doubler and an average of $8.7 \mathrm{~J} / \mathrm{cm}^{2}$ and $3 \sigma$ limit of $14.3 \mathrm{~J} / \mathrm{cm}^{2}$ for 351-nm light 
FIGURE 8. Recent rapid-growth NIF-size boules. The top boule will yield about $11 \mathrm{KDP}$ doublers, and the bottom boule will yield about 12 DKDP triplers. (40-00-0299-0441pb01)
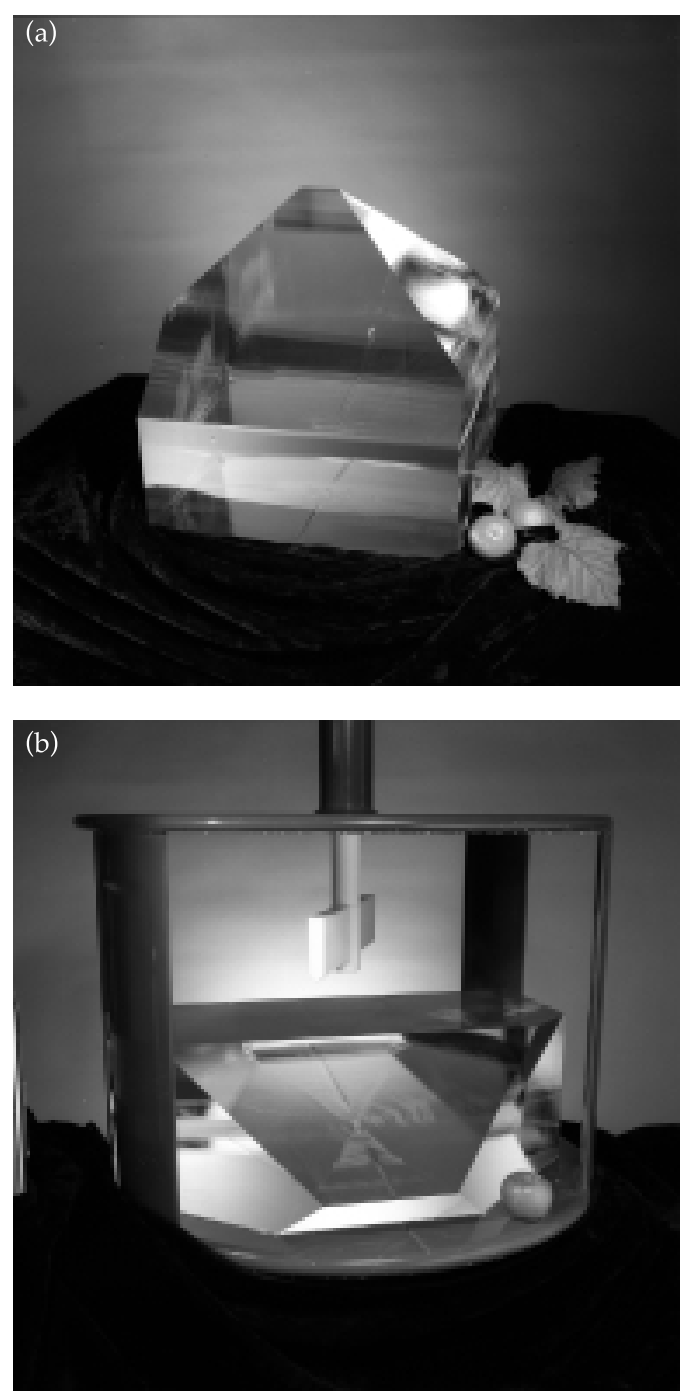

over 3 ns on the DKDP tripler. The allowable damage is equivalent to about 100 pinpoints $/ \mathrm{mm}^{3}$ of crystal volume.

In practice, the allowable damage criterion is more complicated. First, the extent of damage occurring at any given fluence depends on the previous laser exposure of the optic: low-fluence shots tend to condition both KDP and DKDP, resulting in less damage at higher fluences than if the material were initially exposed to the high fluences. Second, since much of the damage occurs in areas of the beam with above-average fluences, the accumulated damage over time depends on how much and how fast the areal fluence distribution changes in the NIF beam over many shots. In addition, the amount of damage occurring in KDP can be reduced by thermally annealing the material.
We made progress during the past year in understanding both the relationship of easily measured, laser-damage distribution curves and how to condition the crystals to minimize damage on-line. Through a combination of constant filtration during growth and thermal annealing of the plates at $160^{\circ} \mathrm{C}$ over several days, damage of KDP at $1053 \mathrm{~nm}$ is not a serious issue. On the other hand, the damage characteristics of DKDP at $351 \mathrm{~nm}$ are more variable for unknown reasons, and much of the material formed under the best conditions as currently understood and preconditioned by low-fluence shots is only marginal at NIF fluences.

To understand laser damage studies, one must first understand the nomenclature and characteristics of the standard tests:

$1 / 1$ a single laser shot of specified fluence

S/1 a set of shots (typically >100) of specified fluence

$\mathrm{N} / 1$ a small sequence of shots from low to high fluence

$\mathrm{R} / 1$ a ramp of many shots (typically $>100$ ) from low to high fluence

In addition, the damage characteristics of any material varies from location to location, so results are ordinarily presented in terms of the distribution of fluences at which a specified amount of damage occurs over many 1-mm beam spots, typically 100 .

Figure 9 shows a comparison of the $S / 1$ and $R / 1$ damage distributions curves for KDP sample 214, both as grown and after thermal annealing. Note that the R/1 damage curve occurs at higher fluence than the corresponding S/1 curve, indicating the beneficial effect of the laser conditioning inherent in an $\mathrm{R} / 1$ experiment. Also note that both the $S / 1$ and $R / 1$ curves shift to higher fluence upon thermal annealing. These results are typical of all KDP samples grown with constant filtration, indicating that thermally annealed KDP normally damages at fluences above that required for the NIF, especially if the laser energy is increased to NIF fluences over several shots. The acceptability of the R/1 threshold is unambiguous, since essentially no damage occurs for the maximum expected NIF fluence, but further clarification is needed for the S/1 case. Even 10\% 


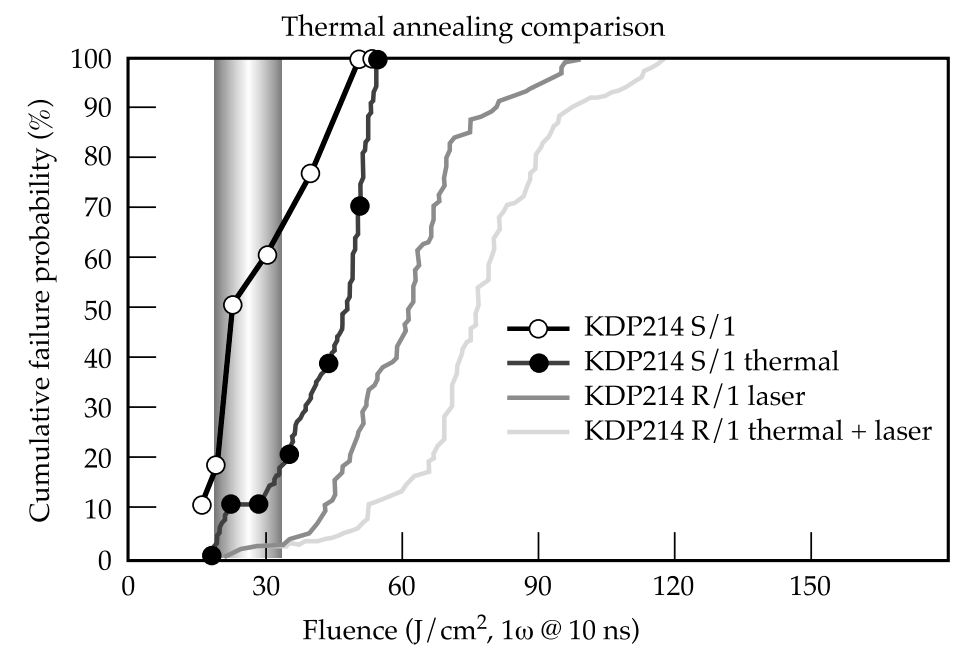

FIGURE 9. Percent of 1-mm aperture beam exposures having detectable damage for a rapidly grown KDP sample exposed to various preconditioning and fluence schedules. The band represents the $4 \sigma$ fluence distribution on the NIF adjusted for pulse length. (40-00-0299-0442pb01) failure probability on this scale for the average NIF fluence is not a problem because damage is detected at a level in which most of the light is still transmitted and the damage pinpoints do not grow.

The situation for damage of DKDP at $351 \mathrm{~nm}$ is less certain because of fewer data, the greater variability of DKDP properties, and the overall proximity to the damage requirement. Furthermore, enhancement of the damage threshold by thermal annealing is not practical because either decomposition or recrystallization occurs at temperatures required for annealing. A summary of all $\mathrm{R} / 1$ data to date for both conventional- and rapid-growth DKDP are shown in Figure 10. Note that the best conventional-growth DKDP has a damage distribution far greater than NIF requirement, indicating that the desired material can be grown. However, the
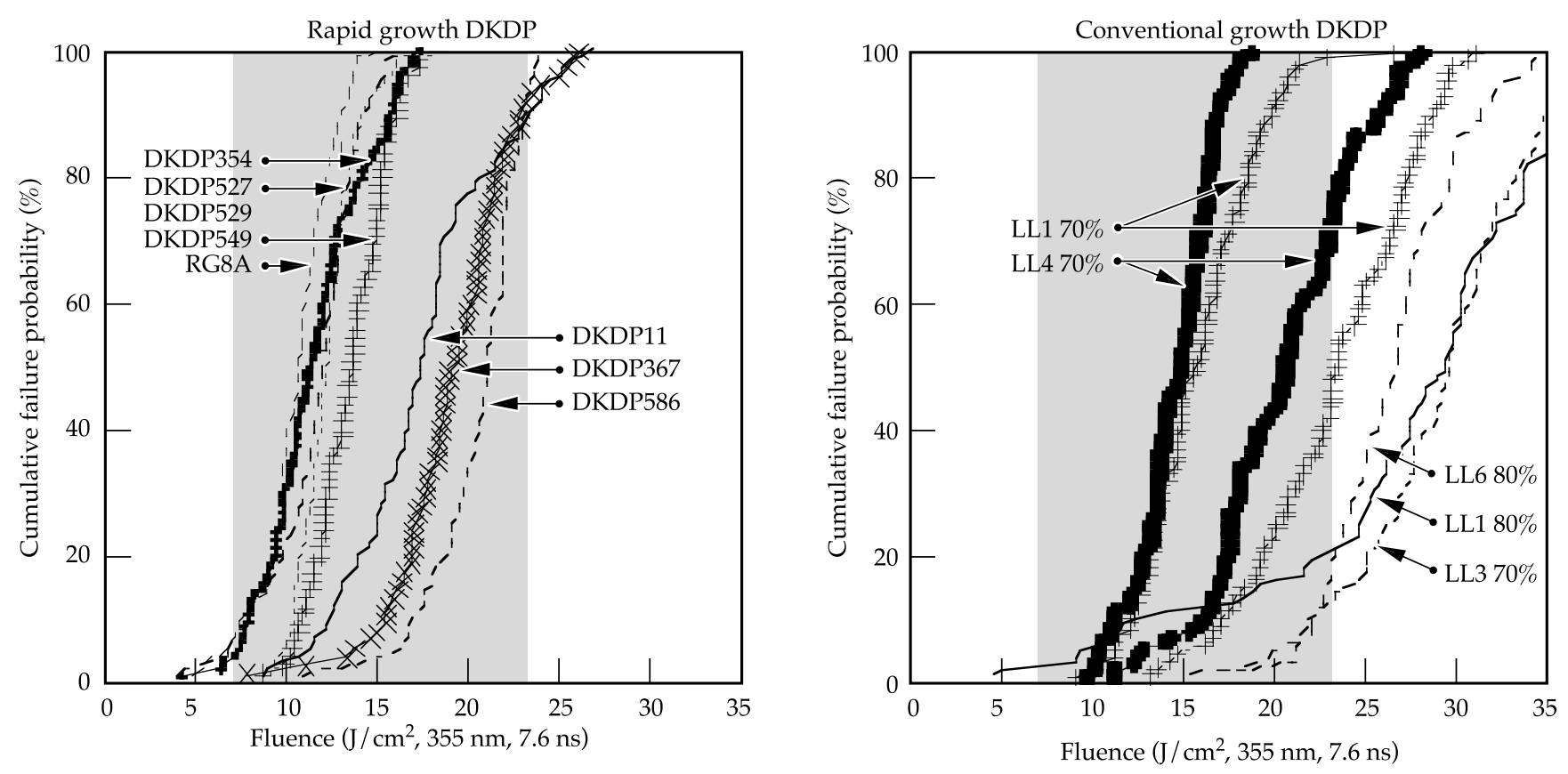

FIGURE 10. Summary of all $3 \omega$ damage data for rapidly and conventionally grown DKDP. To compare to NIF requirements, these fluences are scaled to a 3-ns pulse length by dividing by $(7.6 / 3)^{0.5}=1.6 . \quad(40-00-0299-0443 \mathrm{pb} 01)$ 
FIGURE 11. Relationships among laser fluence, pinpoint bulk damage, and obscuration at NIF fluences. (40-00-0299-0444pb01) (a)

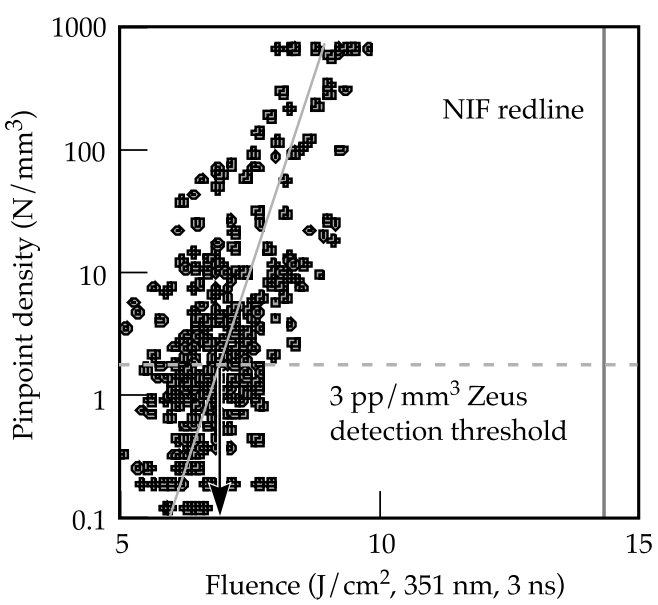

(b)

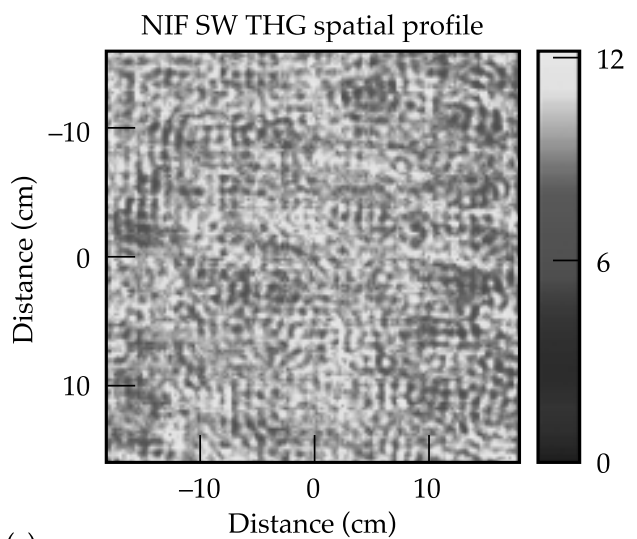

(c)

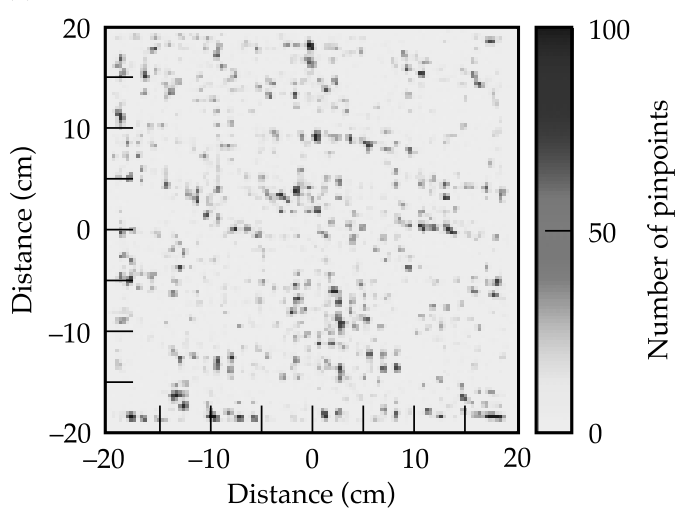

damage threshold is quite variable for reasons not yet completely understood (discussed below), so highly efficient production is not yet in hand.

Because of the proximity of the damage distribution curve of many samples to the NIF fluence distribution, a closer evaluation is appropriate. Sample DKDP11, one of the best by rapid growth, was exposed to a 1-cm-diam, 3-ns, 351-nm beam with the Optical Science Laser (OSL). Pinpoint density and obscured area for a 1-cm-thick crystal is given in Figure 10 as a function of fluence for an N/1 ramp of 8 shots. When this pinpoint density is convolved with the expected NIF beam fluence profile as shown in Figure 11, 0.3\% obscuration is predicted by the time the laser reaches a 1.8-MJ shot. This is close to the desired goal, so the R/1 damage distribution of this sample represents a possible lower acceptable limit.

Crystal RG8A-1 was used to generate 351-nm light on one of the Beamlet experimental campaigns. The crystal was ramped over 9 shots to a maximum fluence of $3.8 \mathrm{~J} / \mathrm{cm}^{2}$ over $1.5 \mathrm{~ns}$, which corresponds to $\sim 5.5 \mathrm{~J} / \mathrm{cm}^{2}$ in $3 \mathrm{~ns}$ and $8.6 \mathrm{~J} / \mathrm{cm}^{2}$ in 7.6 ns assuming a $\tau^{0.5}$ scaling law. Essentially no bulk damage was observed, which is consistent with being at the very beginning of damage for the R/1 curve. An estimate of the pinpoint density vs fluence distribution, convoluted with the measured beam profile on Beamlet, leads to a prediction of about $0.1 \%$ obscuration loss. However, the average NIF full fluence corresponds approximately to the 80-100\% damage level, so RG8A material is not expected to meet the damage requirements of NIF for full-fluence shots. Consequently, the ability to grow NIF-size DKDP boules of sufficient quality by rapid growth is yet to be demonstrated.

However, it is encouraging that several samples of sufficient quality have been grown in 20-L tanks.

While conversion crystals initially installed onto the NIF may see a gradual increase in fluence, and thereby achieve laser conditioning on line, subsequent replacements will not have that opportunity. Moreover, uncertain performance during initial start-up provides some risk to the initial conversion crystals. Consequently, it is highly desirable to provide laser conditioning of the conversion crystals by raster scanning prior to installation. Figure 12 shows the improvement of the $S / 1$ damage fluence distribution with one and two raster preconditioning steps. (The two steps are required because attempts to raster-condition crystals in a single scan 


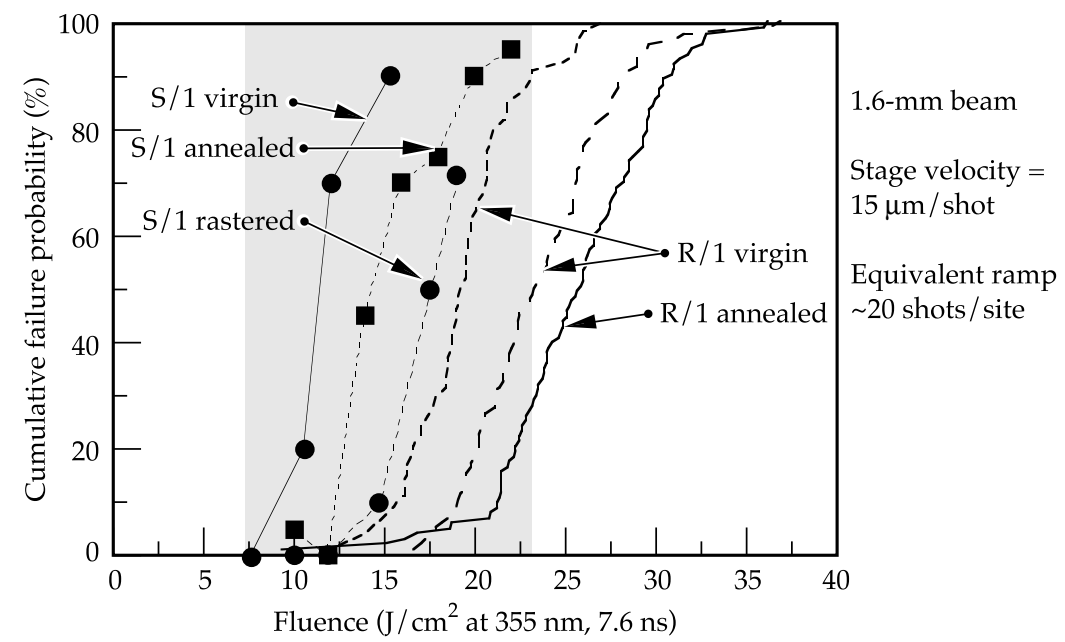

FIGURE 12. Raster conditioning increases $3 \omega$ damage performance of KDP. Two successive raster scans at 10 and $14 \mathrm{~J} / \mathrm{cm}^{2}$ increase the $\mathrm{S} / 1$ performance to near the $\mathrm{R} / 1$ level. (40-00-0299-0445pb01)

is hampered by jitter of the raster beam, which causes too large of fluence jumps.) The two-step preconditioning raises the $S / 1$ damage distribution to near that of the $\mathrm{R} / 1$ curve, demonstrating that off-line conditioning can be an effective way to bring new optics on line.

Considerable effort has been invested in discovering the precise mechanism of bulk laser damage so that the damage threshold can be improved. Recall that the NIF fluence is constrained by damage to the crystals. First, a comparison of preexisting laser scattering sites with subsequent laser damage locations reveals no correlation between scattering and damage at either 1053 or $355 \mathrm{~nm}$, presumably because the scattering sites have negligible absorption. ${ }^{11}$ Similarly, bulk absorption is not related to damage; the 355-nm damage distributions for prism and pyramid material are the same even though the content of dissolved iron and resulting absorption coefficient are substantially different. ${ }^{12}$ Simple thermal calculations show that even a few percent of laser absorption evenly distributed throughout the material should not be a problem, but localized heating from highly absorbing particles in the range of 10-100 nm can easily cause thermal and acoustic shock damage to surrounding material. $\mathrm{FePO}_{4}$ has the required absorption coefficient at $3 \omega$, and addition of $\mathrm{FePO}_{4}$ powder to the growth solution causes a major drop in the $3 \omega$ damage curve. In addition, secondary ion mass spectrometric (SIMS) analysis of the material sputtered from three damage sites showed significant amounts of $\mathrm{Fe}$ and $\mathrm{Cr}$ in addition to major amounts of $\mathrm{Ca}$. Perhaps the $\mathrm{Ca}$ buildup from repeated resaturations causes the formation of mixed cation phosphate precipitates. Further work is in progress to test this hypothesis.

\section{Finishing Development}

Producing finished crystal optics with an aspect ratio of greater than 40:1 from large boules poses a variety of fabrication challenges. Many of the primary specifications for NIF crystals are difficult to meet. Three of the more difficult specifications are related to crystal surface figure and finish and include: short wavelength surface roughness ( $3.0 \mathrm{~nm} \mathrm{rms}$ for $\lambda_{\mathrm{sp}}<0.12 \mathrm{~mm}$ ), surface waviness $(6.4 \mathrm{~nm} \mathrm{rms}$ and power spectral density for $\lambda_{\mathrm{sp}}$ between $0.12 \mathrm{~mm}$ and $33 \mathrm{~mm})$, and $5 \lambda(\lambda=633 \mathrm{~nm})$ peakto-valley surface figure for $\lambda_{\mathrm{sp}}>33 \mathrm{~mm}$. Perhaps the most difficult specification is producing finished crystals oriented with respect to the crystallographic axes such that the average phase matching angle for frequency conversion is accurate to $\pm 15 \mu$ rad (external angle) for doublers and $\pm 30 \mu \mathrm{rad}$ for triplers. Since the phase matching angle is strongly dependent upon use temperature and wavelength, extremely precise finishing machines and metrology tools are required for process control during crystal fabrication. In addition to difficult technical specifications, aggressive cost and 

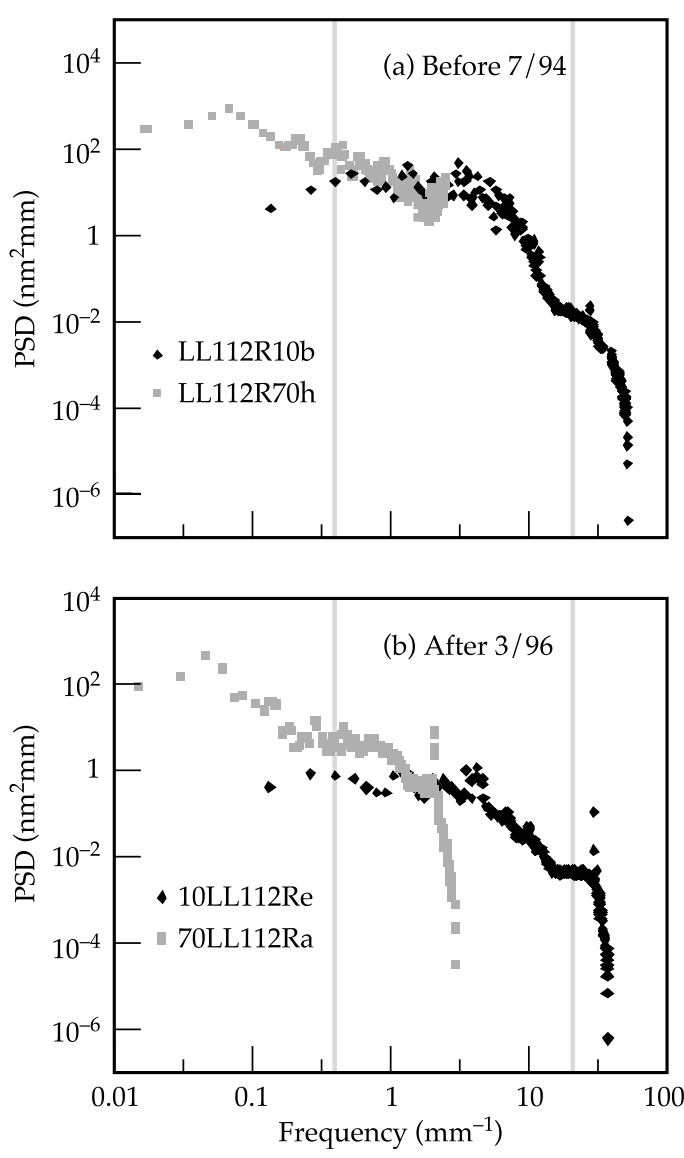

FIGURE 13. Comparison of power spectral density (PSD) for the surface roughness of Beamlet crystals machined on the Pneumo machine at CCI in 1994 and 1996, showing an improvement from 3- to 8-nm roughness to 1 - to 2 -nm roughness. (40-00-0299-0446pb01) production schedules necessitated the development of improved manufacturing process and tools.

Early development activities focused on determining the requirements for long-lead machine tools. The Pneumo Final Finishing Machine at CCI was improved in 1995-96, as illustrated in Figure 13. The inspection data from subsequent parts was used in laser propagation modeling, which validated that diamond-turned parts could meet NIF requirements and established the new finishing machine requirements. However, the Pneumo machine is 20 years old, undersized, and cannot finish parts in the time required. Consequently, a new machine was designed and fabricated by the Moore Tool Company. The resulting machine, shown in Figure 14, is currently undergoing performance acceptance test at LLNL.

While roughness, waviness, and wedge are controlled by the final finishing machine, optical figure is largely determined by the blank fabrication process. Again, current development activities can be traced back several years. The Nova fabrication and finishing process could not reliably produce finished crystals meeting NIF figure requirements. As a result, CCI modified its proprietary blank fabrication process in 1995 during Beamlet crystal production, and the new process has been used to produce many large-aperture crystals that meet NIF figure requirements. As shown in Table 2, the process of producing flat blanks is now well in hand. Again, however, the CCI machines are old, undersized, and too slow to meet NIF production schedules.
FIGURE 14. The Moore Final Finishing Machine has now been assembled and is undergoing acceptance testing. (40-00-0299-0447pb01)

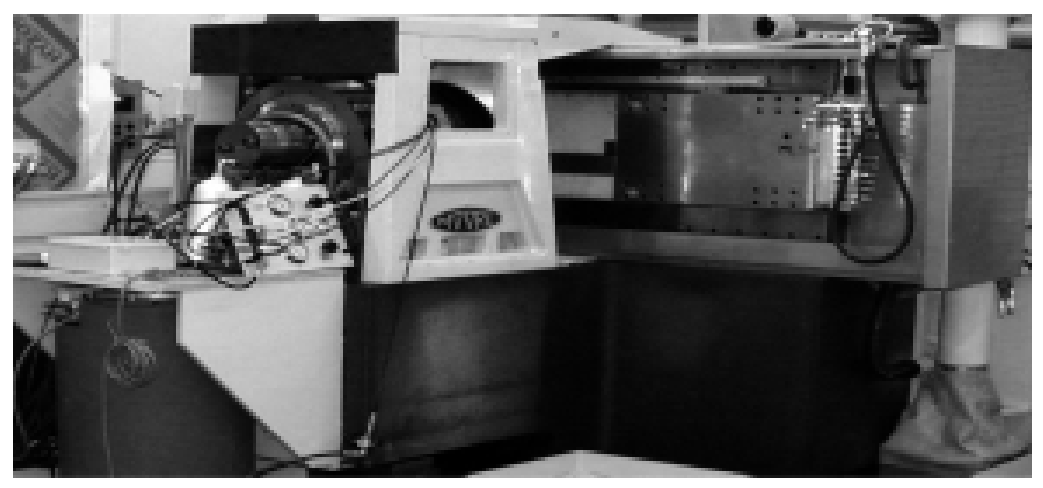


TABLE 2. A summary of crystals produced for Beamlet since 1996 shows that the flatness process can meet NIF specifications at high yield.

\begin{tabular}{|cc}
\hline Crystal & $\begin{array}{c}\text { Surface figure } \\
\text { (waves @ } \lambda=633 \mathrm{~nm} \text { ) }\end{array}$ \\
\hline $328-4$ & 8 \\
$328-5$ & 5 \\
$328-6$ & 4 \\
RG8B-1 & 2.2 \\
RG8B-2 & 2.3 \\
RG9B & 2.1 \\
345-1 & 4.5 \\
$70 \%$ LL37-1 & 1.1 \\
LL6-11 & 4.5 \\
\hline
\end{tabular}

Consequently, Lawrence Livermore National Laboratory (LLNL) started developing a new set of custom machine tools in 1997: a boule-facing machine, a profiling mill, and three flatness machines. The flatness machine is the most challenging of the three types. It must produce surfaces that meet the flatness requirements for $\lambda_{\text {sp }}>33 \mathrm{~mm}$. A model of it is shown in Figure 15, and the first machine is nearing dry-cut testing. Three $z$-axis slides provide approximately $100 \mathrm{~mm}$ of vertical travel and up to 0.25 degrees of tip and tilt. Compliance tests performed on the z-axis last summer determined the stiffness of the z-axis-an important metric on precision

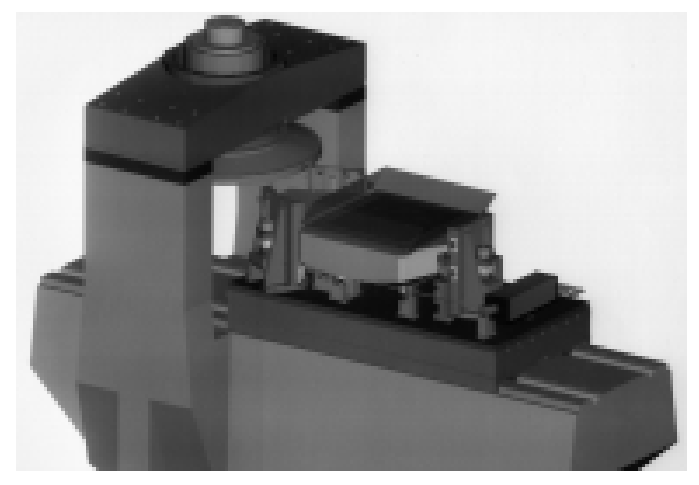

FIGURE 15. The LLNL Prototype Flatness Machine design is highly integrated to reduce complexity during machine assembly. (40-00-0299-0448pb01) machine tools-to be $36 \mathrm{~nm} / \mathrm{N}$ $(6.5 \mu \mathrm{in} . / \mathrm{lb})$. This is actually slightly better than the existing Pneumo machine and leaves open the possibility that the basic machine design may be good enough to allow one of the flatness machines, with modest upgrading to remove roughness and waviness at scale lengths $<33 \mathrm{~mm}$, to serve as a backup final finishing machine.

Precise crystal orientation is perhaps the most difficult finishing specification.

Beamlet tests in 1997 revealed spatial variations in frequency conversion efficiency that related to bulk crystal features, making the orientation process even more challenging. At the time, the only off-line method that existed for predicting frequency conversion performance of crystals involved using subaperture lasers to measure variations in their phase matching angles. The only production tool for this purpose was the Crystal Orientation Measurement System (COMS) at CCI. COMS compares the peak of the tuning curve of a proof crystal and a crystal being tested by comparing the amount of laser energy converted by each crystal as both are rocked in parallel beams on a common mount. However, the COMS configuration could only be used to access two points on each crystal.

Diagnostic techniques developed during Beamlet frequency conversion experiments have provided a breakthrough in this regard. Variations in frequency conversion efficiency correlate very well with variations in crystal birefringence determined simply by subtracting the transmitted wavefront through crystals at two orthogonal polarizations corresponding to the " $\mathrm{o}$ " and " $\mathrm{e}$ " transmission axes. ${ }^{13}$ This technique, now called "orthogonal polarization interferometry" (OPI), provides a valuable alternative to mechanically complex twodimensional scanning for determining the relative phase matching angles across the full aperture of crystals. However, OPI determines only the relative values across the crystal, not the absolute phase matching angle needed for NIF production.

The Crystal Alignment Test System (CATS), now under development, relies on OPI to determine the distribution of phase matching angles across a crystal. Small beam frequency conversion data from the CATS 
will supplement the OPI with absolute phase matching angles for a line of points along the crystal. The two data sets can then be correlated to provide a map of the absolute phase-matching angle at all points on the crystal and an average phase matching angle that is used to correct crystal orientation during final finishing operations.

The CATS design, shown schematically in Figure 16, is conceptually very similar to the existing COMS in that each measurement is referenced to a precisely oriented proof crystal. Two parallel beams pass through the proof and test crystals, which are mounted on a single diamond-turned chuck. Pentaprisms are used to produce two parallel beam paths, thereby greatly simplifying the mechanical and controls requirements of the system. Because frequency conversion crystals are insensitive to out-of-plane rotation errors in the pentaprisms, there is no need to compensate for slide straightness errors or adjust beam alignment at each point in the scan line. During operation, one beam samples the proof while the other samples the crystal to be tested. The mount is rocked, and converted power is measured in both channels. The resulting tuning curves are curve-fit to determine the phase matching angle offset between the two crystals.

The use of calibrated proof crystals in CATS greatly reduces the sensitivity of the measurements to systematic errors, including temperature, laser wavelength, pointing jitter, etc. For example, by comparing crystals to a known proof, only the relative temperature between the proof and the crystal being tested must be controlled. The system is also insensitive to variations in laser wavelength between the NIF use wavelength and the CATS laser, since both the proof and crystal being tested see the same wavelength. There is only a minor error introduced if the deuteration level of a tripler crystal being measured is different from the tripler proof.

\section{Conclusions}

Rapid growth has now grown numerous boules of NIF size. The technical challenge for KDP is to increase process reliability and doubler yields to minimize costs, as all performance specifications have been achieved. Thermal annealing is an important aspect of meeting those specifications. The principal technical challenge for DKDP is to increase $3 \omega$ damage threshold at full size to the NIF requirement. The best DKDP grown in small tanks has better $3 \omega$ damage properties than needed for the NIF, but that level has yet to be demonstrated in large boules.

The Moore Final Finishing Machine, flatness machines, and CATS together form the primary foundation needed to meet the most difficult of the crystal finishing specifications. The Moore Final Finishing Machine is undergoing final testing. Mechanical assembly of the LLNL Prototype Flatness Machine is nearly complete, and compliance tests were very
FIGURE 16. The conceptual layout of Crystal Alignment Test System reveals many similarities to COMS, its predecessor. (40-00-0299-0449pb01)

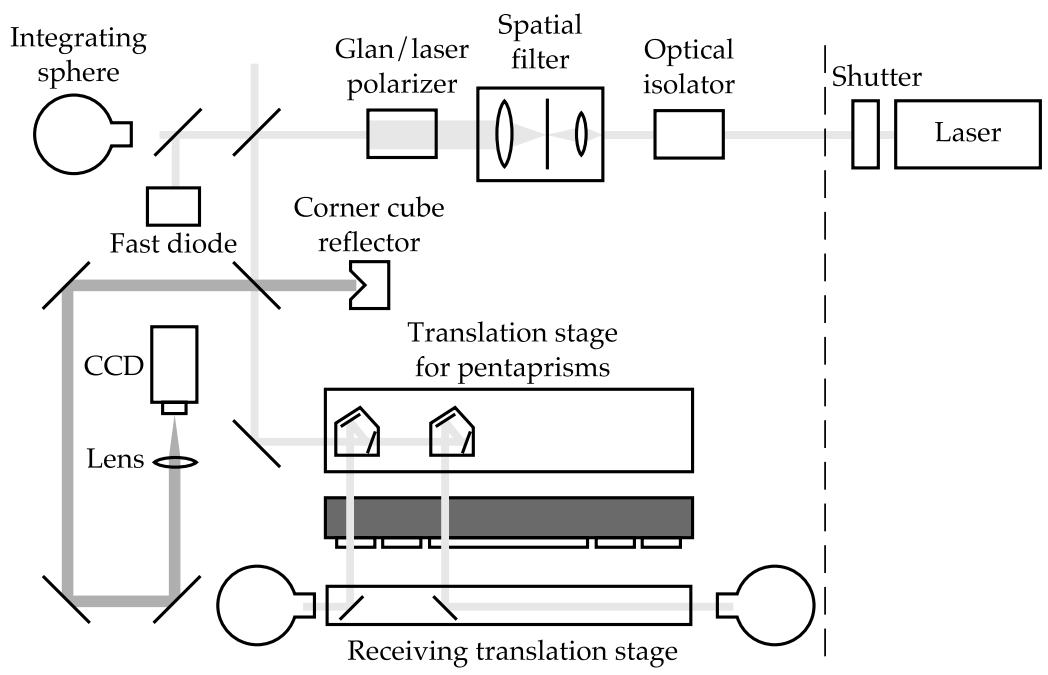


successful. A new CATS design takes advantage of new metrology techniques, and construction of several subsystems are ready to begin.

\section{Acknowledgments}

This work represents the efforts of dozens of people including Leslie Carman, Igor Smolsky, Sergey Potapenko, Martin DeHaven, Randy Floyd, Dick Spears, Mike Martin, and Warren Bell in the growth area, and Mary Norton, Jerry Auerbach, Larry Morris, Sue Locke, Gale Johnson, Sam Thompson, Gregg Wilkinson, Dave Kennedy, Stan Locke, Frank Gonzales, Dannie Johnson, Charles Cass, Blaine Beith, Mercedes Dickerson, George Weinert, Timm Wulff, Richard Arney, Dan Schumann, Inge Fine, Wayne Olund, and Chris Steffani in fabrication support.

\section{Notes and References}

1 N. P. Zaitseva, J. J. De Yoreo, M. R. DeHaven, R. L. Vital, L. M. Carman, and H. R. Spears, J. Crystal Growth 180, 255-262 (1997).

2. N. P. Zaitseva, I. L. Smolsky, and L. N. Rashkovich, Krystallografiya 36, 198 (1991).

3. J. J. De Yoreo, T. A. Land, L. N. Rashkovich, T. A. Onischenko, J. D. Lee, O. V. Monovskii, and N. P. Zaitseva, J. Crystal Growth 182, 442-460 (1997).
4. N. P. Zaitseva, L. Carman, I. Smolsky, R. Torres, and M. Yan, "The effect of impurities and supersaturation on the rapid growth of KDP crystals," submitted to J. Crystal Growth.

5. L. N. Rashkovich and N. V Kronsky, J. Crystal Growth 182, 434-441 (1997).

6. H. Robey, R. Floyd, R. Torres, and A. Burnham, "Impurity leaching rates of 1000 liter growth tanks," Lawrence Livermore National Laboratory, Livermore, CA, UCRL-ID-133365.

7. N. Zaitseva, J. Atherton, R. Rozsa, L. Carman, I. Smolsky, M. Runkel, R. Ryan, and L. James, "Connection between continuous filtration and dislocation structure of KDP crystals," submitted to J. Crystal Growth.

8. H. F. Robey and S. Potapenko, "Ex-situ microscopic observation of the lateral instability of macrosteps on the surface of rapidly grown $\mathrm{KH}_{2} \mathrm{PO}_{4}$ crystals," submitted to J. Crystal Growth.

9. H. F. Robey, S. Potapenko, and K. Summerhays, "Bending of steps on rapidly grown $\mathrm{KH}_{2} \mathrm{PO}_{4}$ crystals due to an inhomogeneous surface supersaturation field," submitted to J. Crystal Growth.

10. M. Runkel, J. De Yoreo, W. Sell, and D. Milam, "Laser Induced Damage in Optical Materials: 1997," in Proc. SPIE, vol. 3244, pp. 51-63.

11. B. Woods, M. Runkel, M. Yan, M. Staggs, N. Zaitseva, M. Kozlowski, and J. De Yoreo, "Laser Induced Damage in Optical Materials: 1996," in Proc. SPIE, vol. 3244, pp. 20-31.

12. M. Runkel, M. Yan, J. De Yoreo, and N. Zaitseva, "Laser Induced Damage in Optical Materials: 1997," in Proc. SPIE, vol. 3244, pp. 211-222.

13. P. J. Wegner et al., Frequency Converter Development for the National Ignition Facility, Lawrence Livermore National Laboratory, Livermore, CA, UCRL-JC-129725. Prepared for Proc. $3^{\text {rd }}$ Intl Conf on Solid State Lasers for ICF. 